\title{
Stem Cells in Neurodevelopment and Plasticity
}

Flora M. Vaccarino, M.D., Yosif Ganat, Yuchun Zhang, M.D., and Wei Zheng, M.D.

The processes of stem cell proliferation and differentiation during embryogenesis are governed by transcription factors that regulate the regional differentiation of the central nervous system (CNS). Do neural "stem" cells persisting in the postnatal CNS disobey this sequence of events? The division of neural progenitor cells is promoted by basic Fibroblast Growth Factor Fgf2 or Epidermal Growth Factor Egf. However, while the intraventricular administration of FgF2 during embryogenesis increases the generation of cortical pyramidal neurons, the same treatment in the adult CNS produces interneurons of the olfactory bulb. The competence of neural progenitor cells to respond to $F g f$ is dictated by nuclear transcription factors that constrain neuronal fates through time. Developmentally regulated transcriptional programs are regulated by cell interactions, as dividing cells check their molecular signature against that of their environment. Thus, cell surface interactions account for competitive phenomena among pools of cells, including the inhibitory effect of neurons on the division of their progenitors, and may also explain the "permissive" effects of non-CNS environments. The challenge remains to understand the genetic programs that control the fate of progenitor cells within the postnatal CNS and their regulation by stress, apoptosis and environmental perturbations. These programs are likely to be similar to gene cascades that control proliferation, differentiation and migration of progenitor cells at earlier stages of development. [Neuropsychopharmacology 25:805-815, 2001] (C) 2001 American College of Neuropsychopharmacology. Published by Elsevier Science Inc.
KEY WORDS: Fibroblast growth factor; Fgf1 stem cell; Neural; Homeobox; Regeneration plasticity; Stress

\section{STEM CELLS IN A DEVELOPMENTAL PERSPECTIVE}

The human central nervous system (CNS) is one of the most remarkable products of evolution, and the neural substrate of our mental functions. Anatomy and embryology show us that the fundamental structure of the neural tube has been preserved during the past 400 million years of evolution. The genes that govern CNS morphogenesis are evolutionarily conserved families of

From the Child Study Center and Section of Neurobiology Yale University, New Haven, CT

Address correspondence to: Flora Vaccarino, Yale University Child Study Center, 230 South Frontage Rd, New Haven, CT 06520, Tel.: (203) 737-4147, Fax: (203) 785-7611, E-mail: Flora.vaccarino@ yale.edu

Received July 18, 2001; revised August 8, 2001; accepted August 9, 2001. transcription factors. The construction of the CNS proceeds through successive phases of gene expression that progressively restrict the potential of progenitor cells. Before organogenesis, broadly expressed gene products define embryonic polarity and distinguish the brain from the neural tube. During later phases of development, progenitor cells are subdivided into fields each characterized by a distinct pattern of transcriptional regulators that will eventually direct the differentiation of specific sets of neurons. Cell specification and differentiation is tightly coupled to cell growth through mechanisms that are still largely unidentified.

The recent rediscovery of Altman's original findings (Altman 1962; Altman and Das 1966) that neurogenesis still occurs in the adult mammalian brain, including humans (Eriksson et al. 1998b), apparently contradicts the rules of this tightly orchestrated sequence of developmental events. Neuronal progenitors have been identified in the adult hippocampal subgranular zone and the telencephalic subventricular zone (SVZ); these cells give rise to new neurons that migrate to the dentate gy- 
rus and the olfactory bulb, respectively (Cameron et al. 1993; Lois and Alvarez-Buylla 1993; Luskin 1993; Morshead et al. 1994).

In vitro studies have identified neuroepithelial cells that undergo self-renewal and are capable of giving rise to diverse progeny, including neurons, astrocytes, and oligodendrocytes (Figure 1) (Reynolds and Weiss 1992; Richards et al. 1992; Davis and Temple 1994). These progenitor cells have been called "neural stem cells." Neural stem cells have been isolated from various regions of the embryonic neural tube and from the adult SVZ (McKay 1997; Temple and Alvarez-Buylla 1999). Upon transplantation, in vitro cultured stem/progenitor cells from the hippocampus or the SVZ are able to populate other brain regions, suggesting a broader developmental potential (Suhonen et al. 1996; Lim et al. 1997). These studies have suggested that the normal adult CNS contains neural progenitor cells that are capable of integrating into different sites and perhaps give rise to a large variety of mature cell types.

Are stem cells able to escape the progressive restriction of cell fates that occurs over the course of development, or are stem cells still subjected to cell fate restric-

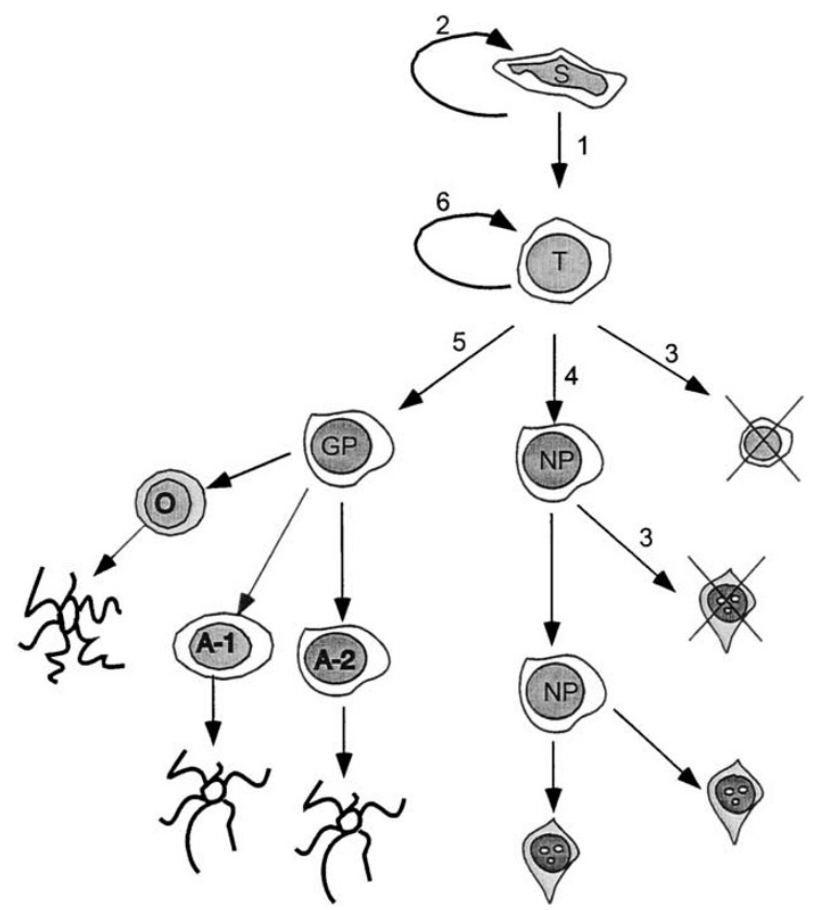

Figure 1. Stem cell lineage. Stem cells (S) self-renew and generate transit-amplifying cells $(\mathrm{T})$ which in turn differentiate into committed neuronal progenitors (NP) or glial progenitors (GP). These will give rise to oligodendrocyte progenitors $(\mathrm{O})$ or type 1 and type 2 astrocyte progenitor cells (A-1 and A-2). The stem cell is shown to divide asymmetrically, although its mode of division is actually unknown. It is assumed that NP, GP, and their progeny have a finite number of divisions and represent the vast majority of cells within the pseudostratified ventricular epithelium (PVE) or the postnatal subventricular zone (SVZ). Crossed cells represent cell death. tion rules in vivo? There are several issues to be resolved. The first is whether a cell that is able to generate neurons and glial cells is a truly multipotential cell. This question is especially relevant since it has been discovered that neurons can be generated from cells of glial lineages, such as radial glia and astrocytes, suggesting that neurons and glia belong to the same lineage (Doetsch et al. 1999; Malatesta et al. 2000; Noctor et al. 2001). Furthermore, stem cells isolated from postnatal CNS have not been able to generate widely different neuronal lineages and neuronal types such as pyramidal cortical neurons, cerebellar Purkinje cells or hippocampal pyramidal neurons, either in vitro or after transplantation in vivo.

The idea of multipotential stem cells that can be induced by soluble factors to give rise to all the adult cell lineages of a certain tissue was developed in the hematopoietic system (reviewed in Anderson 2001). This concept may not be entirely applicable to the CNS, which undergoes a complex regional differentiation and where cells permanently occupy a certain location that is essential for their function. During development, lineage restriction occurs along compartment boundaries; because in the CNS cellular differentiation is tightly coupled to the region of the neuroepithelium from where the cell develops, genes that regulate CNS pattern formation may be key for stem and progenitor cells to develop their unique neuronal phenotypes. At the present state of knowledge, we can conclude that stem cells are able to generate neurons and glia but may remain confined within a certain lineage, which is linked to the regional and temporal specification of the cells of origin (cortical versus spinal cord, for example). It remains to be seen whether, after simplified in vitro growth conditions, stem and progenitor cells can lose the set of genetic programs that are operative in the intact CNS and whether they can be induced to re-program themselves. This may depend on our capability of identifying the molecular principles governing stem cell proliferation and regional differentiation.

In this paper, we will briefly review the properties of stem cells over the course of development. Much has to be learned from comparing mechanisms operating during early development, as these are likely to be reused within adult stem cells. We will argue that the commitment and cell fate restriction of stem cells has not been adequately examined. Understanding the genetic mechanisms that are able to program these cells toward particular fates during embryogenesis are key to exploiting this emerging field for therapeutic purposes.

\section{EMBRYONIC STEM CELLS}

Before the onset of neurogenesis, progenitor cells throughout the CNS express regulatory genes that subdivide each region into compartments and regulate their size (Puelles and Rubenstein 1993; Rubenstein and 
Shimamura 1997). Many of these genes are transcription factors of the homeodomain class. These genes are at the top of a hierarchy of genetic programs that specify cell fates, growth and neuronal connections. Progenitor cells generate neurons during early to mid-embryogenesis. Neurons progressively migrate to their target sites, some of them carrying with them the legacy of transcription factors expressed by their progenitors. For example, the homeodomain gene Otx1, expressed in a decreasing antero-posterior gradient by cortical progenitor cells, continues to be expressed by their cortical neuron progenies (Simeone et al. 1992; Frantz et al. 1994).

Stem cells (embryonic stem cells or ES cells) that develop from the inner cell mass of the early postimplantation embryo are truly totipotent cells that give rise to all tissues of the developing organism, including neural tissue. ES cells can be grown and maintained in vitro without loss of totipotency in the presence of Leukemia Inhibitory Factor (LIF). The process of ES cell differentiation is characterized by differential expression of transcription factors by daughter cells and their spatial segregation, migration and sometimes intermixing. ES cells first differentiate into the three germ layers, ectoderm, endoderm and mesoderm. Neural tissue arises within a restricted area of the ectoderm by a suppression of the epidermal fate in ES cells. Ectodermal cells or ES cells readily acquire generic neuronal markers in vitro by dissociation and low-density culture, suggesting that neural fate is perhaps a "default" state for ES cells (Hemmati-Brivanlou and Melton 1997; Tropepe et al. 2001). Neural fate is suppressed by Transforming Growth Factor $\beta$ (TGF- $\beta$ ) signaling, which actively promotes epidermal differentiation. In vivo, neural-inducing molecules are actually TGF- $\beta$ antagonists (noggin, follistatin, chordin) that inhibit TGF- $\beta$ signaling and epidermal fate, allowing neural differentiation in restricted portions of the embryo (Beddington and Robertson 1999).

Fibroblast growth factors (Fgf) are required from the very onset to promote differentiation within the neural lineage (Pownall et al. 1996; Hongo et al. 1999; Tropepe et al. 2001) (Figure 2). Thus, the antagonism of TGF- $\beta$ signaling and the local release of an Fgf may allow the emergence of generic progenitors of the neural lineage, or primitive neural stem cells, much before definitive nerve cells are born. The molecular mechanisms by which primitive neural stem cells may directly derive from ES cells are not clearly understood. Most likely, Fgf cooperates with LIF to induce the expression of nuclear transcription factors that "switch on" neural programs of gene expression. By contrast, LIFinduced Stat-3 may induce the homeodomain transcription factor Oct-3/4 to control the differentiation of ES cells into primitive endoderm and mesoderm (Niwa et al. 2000). Each step in the progressive commitment and differentiation of stem cells is characterized by the expression of unique patterns of homeodomain genes and growth factor receptors (Vaccarino 2000). Some of the growth factors in- volved in this time and region-dependent differentiation are schematically shown in Figure 2.

Primitive neural stem cells developing directly from ES cells have a wider potential as they can contribute to many tissues in all germ layers upon transplantation, and express neural as well as endodermal markers. In contrast, neural stem cells isolated at E8.5 from the CNS have apparently lost this potential (Tropepe et al. 2001). Similar studies suggest that neural stem cells are already committed to a regional fate by E12.5 in mouse (Olsson et al. 1997). Thus, neural stem cells may undergo a progressive fate restriction, along which they show different growth factors requirements. However, in vitro expanded adult stem cells have been reported to generate cells of the mesodermal lineage such as muscle or blood (Bjornson et al. 1999; Galli et al. 2000). How do we reconcile or understand these divergent findings?

Because progenitor cells isolated from later stages of development and transplanted into younger CNS have been largely unable to generate cells typical of the earlier period, neural cells are thought to permanently restrict

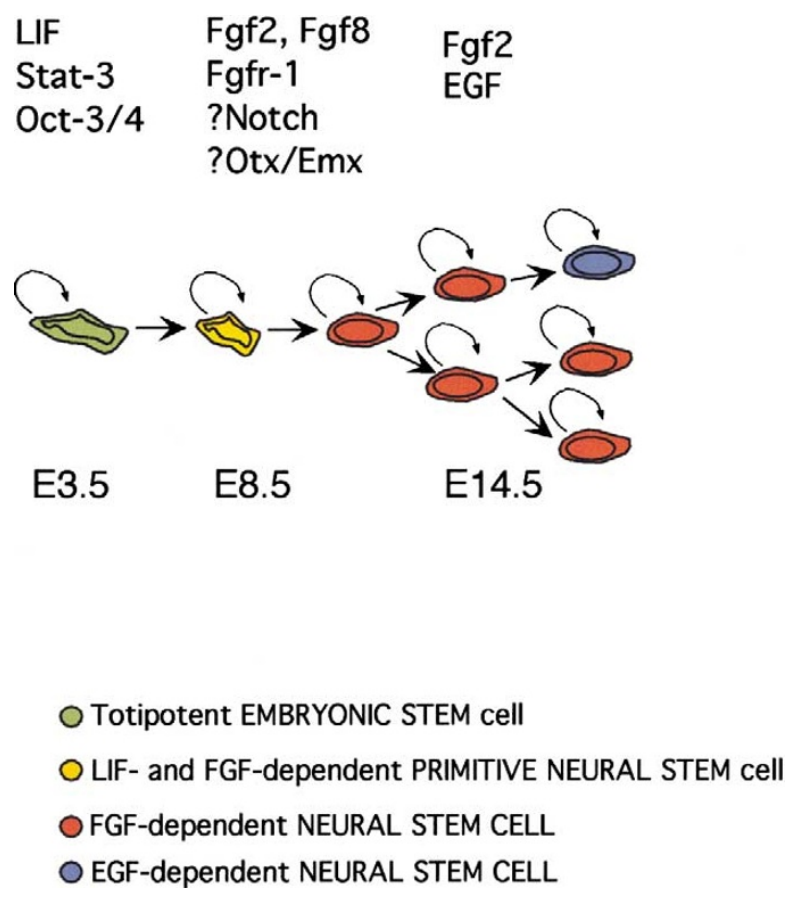

Figure 2. Simplified model of the hypothesized lineage of stem and progenitor cells. At the top, some of the transcription factors and signaling molecules critical for proliferation and fate commitment are listed for stem cells at the stages shown. The middle portion, redrawn from Tropepe at al. (2001) shows the evolution and progressive differentiation of totipotent ES cells (green) first into pluripotent primitive neural stem cells (yellow) and then into neural stem cells committed to the neural lineage (red). Embryonic stages (E) at which the corresponding cells have been isolated are shown. Neural stem cells responding to either Fgf2 (red) or EGF (blue) differentiate into committed neuronal and glial progenitors, which in turn differentiate into neurons and glia. 
A

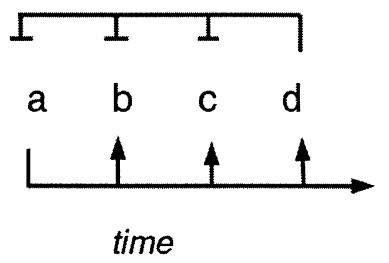

B

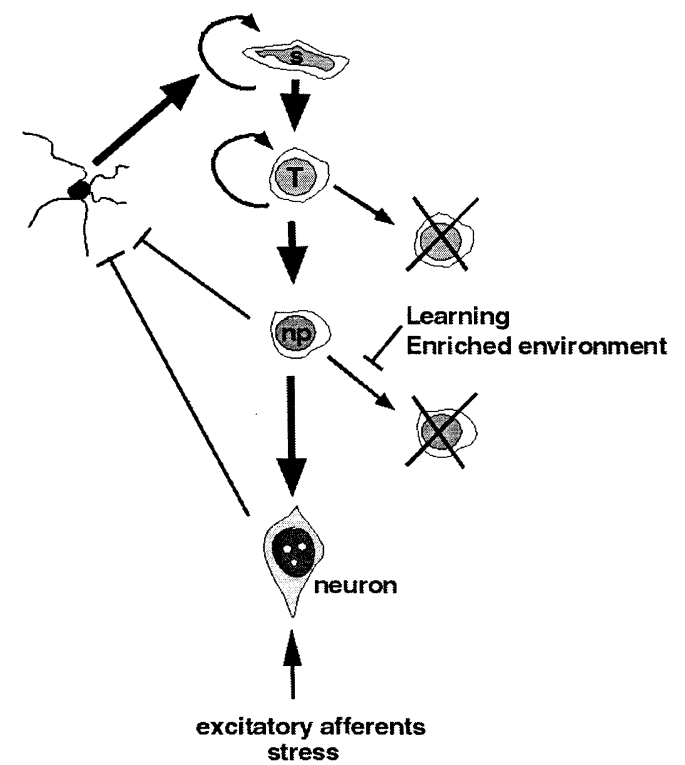

Figure 3. Regulation of stem cells by the environment. Panel A: Schematic diagram of a developmental progression in fate. Stages " $a$ " through " $d$ " represent developmental waves of gene expression in progenitor cells; arrows and bars indicate positive and negative regulation, respectively. Stage "a" may be congruent with " $b$ " or any of the subsequent stages because it is able to induce positive signals that upregulate gene expression and corresponding surface codes to match that of the later environments. In contrast, cells in " $\mathrm{d}$ " may not be able to regulate their surface properties to match those of earlier environments because of the presence of strong transcriptional repressors. Panel B: Neuronal progenitors and neurons are thought to exert a tonic inhibitory effect on stem cell proliferation by way of decreasing the release of an astrocyte mitogen such as Fgf2. Thus, the death of either neuronal progenitors or mature neurons should release stem cells from this inhibition, explaining the stimulatory effect on neurogenesis of deafferentation or neuronal apoptosis. Learning and enriched environments are thought to prevent the apoptosis of neuronal progenitors or newly generated neurons. Neuronal progenitors may be a form of radial glia. Symbols as in Figure 1.

their potential (McConnell 1990; Lumsden 1991). Fate restriction is thought to be mediated by transcription factors that self-maintain their own expression and repress transcriptional regulators expressed at earlier stages of development (Figure 3, Panel A). This could independently occur in adjacent compartments of the CNS.

This general idea accounts for the observation of competitive interactions among pools of cells during development, including the known inhibitory effect of neurons on the division of their progenitors, both in the hippocampus and the olfactory epithelium (Figure 3, Panel B) (Gould and Tanapat 1997; Calof et al. 1998). Most certainly these effects are not cell autonomous but require cell interactions, involving adhesion molecules and other signaling factors that reflect the intrinsic history of the cells. Dividing cells may "sense" their environment at specific phases of the cell cycle and check their molecular signature against that of their environment, a well-known developmental phenomenon called "community effect" (Gurdon 1988; Gurdon et al. 1993). The inability of the progenitor cells to adjust to their environment may result in their reception of "incongruent" signals, producing cell cycle arrest. Such situations may be their transplantation into a younger environment or the accumulation of their own progeny. The "stop" or "go" signals may involve the synthesis of universal regulators of the cell cycle or growth factor receptors (see Molecular Mechanisms of Stem Cell Differentiation). In conclusion, the environment may play a critical role in the implementation of the potential of a stem or progenitor cell. Certain non-CNS environments, such as the bone marrow, may be more permissive and/ or are able to exert a much stronger "community effect".

These molecular signals are likely to be involved in the termination of cortical neurogenesis. During the time period E11-E17, the generation of neuronal progenitors from stem cells first rises and then, after about E14.5, becomes progressively lesser than their differentiation into neurons. Consequently the proportion of progenitor cells that exit the cycle dramatically increases, effectively ending neurogenesis (Takahashi et al. 1996). These dynamics suggest that the generation of transit-amplifying cells and/or neuronal progenitor cells sharply declines during the late embryonic period (steps 1 and 4 in Figure 1). Alternatively, it is possible that neuronal progenitors lack critical survival factors and the majority of them die rather than differentiate (step 3 in Figure 1). Possible molecular mechanisms are the downregulation of critical growth factors and homedomain genes that may be necessary for the generation or survival of neuronal progenitors from stem cells. A typical example is Otx1 and Fgf2 in the cerebral cortical neuroepithelium (Frantz et al. 1994; Vaccarino et al. 1999a; Vaccarino 2000).

\section{MOLECULAR MECHANISMS OF STEM CELL DIFFERENTIATION}

Positive and negative interactions between extracellular growth factors including the Sonic Hedgehog (Shh), Wing- 
less (Wnt), or Fgf and homeodomain genes are likely to regulate the regional and cellular differentiation of neural stem cells. These signaling systems may play an important role in inducing appropriate "waves" of transcription factors in progenitor cells (arrows in Figure 3, Panel A). Wnt and Shh are required for the generation of neuronal cell groups within the mesencephalon and spinal cord, respectively (McMahon and Bradley 1990; Hynes et al. 1995; Ericson et al. 1997; Jessel and Lumsden 1997; Lee et al. 1997).

The Fgf family comprises 22 ligands and four receptors, of which two, Fgfr-1 and 2, are important for CNS development. It is tempting to speculate that individual Fgf ligands and receptors are necessary for the growth of specific regions of the CNS. For example, the disruption of the Fgf8 gene causes the absence of a portion of the mesencephalon and the cerebellum (Meyers et al. 1998), whereas the lack of Fgf2 decreases the number of cells within the cerebral cortex (Ortega et al. 1998; Vaccarino et al. 1999b). In addition, Fgf8 ectopically expressed in the diencephalon can induce the growth of midbrain or cerebellar tissue in this new location (Crossley et al. 1996). Fgf8 changes the fate of progenitor cells from forebrain into anterior hindbrain by inducing homedomain genes that are normally expressed in the mesencephalic/metencephalic junction. Thus, Fgf8 represses Otx2 and Pax6 (typical of the forebrain) and enhances the expression of En1/2, Wnt-1 and Gbx2 (typical of the mesencephalon or cerebellum) (Liu et al. 1999; Martinez et al. 1999; Liu and Joyner 2001). Because these actions are exerted in the embryonic neuroepithelium, before the onset of neurogenesis, it is likely that Fgf-homeodomain interactions modify the fate of stem cells and their progeny.

In contrast, the exogenous delivery of Fgf2 in the embryonic lateral ventricles increases the generation of cortical pyramidal neurons (Vaccarino et al. 1999b). In the forebrain, Fgf2 is expressed in the dorsolateral cortical neuroepithelium (pseudostratified ventrical epithelium, or PVE) overlapping the expression of Otx1 and Pax6 mRNAs (Vaccarino et al. 1999b). Fgf2 increases the number of the embryonic progenitors for cortical pyramidal neurons in vitro and the expression of Otx2 and Emx genes in these progenitors (Robel et al. 1995; Vaccarino et al. 1995). Fgf2 null mutant mice have a 50\% reduction in cortical progenitor cell number before the beginning of neurogenesis (Raballo et al. 2000). In the absence of Fgf2, approximately $40 \%$ of pyramidal glutamatergic neurons of the neocortex are not generated (Korada et al., submitted). In conclusion, two different Fgf ligands, Fgf2 and Fgf8, may be required for the proliferation or differentiation of stem cells or their progeny in different CNS regions. These region-specific effects may be explained by reciprocal interactions between Fgfs and regional patterns of homeodomain gene expression.

In contrast to the above results in vivo, basic Fgf (Fgf2) added in vitro will enhance the proliferation and differentiation of neuroepithelial stem cells from various CNS regions, including the hippocampus and the spinal cord (Ray and Gage 1994; Vaccarino et al. 1995; Mayer-Proeschel et al. 1997). However, there are no abnormalities in cell number within the hippocampus in Fgf2 knockout mice. Similarly, Fgf2 is not necessary for the production of GABAergic interneurons from the basal ganglia. A likely explanation is that Fgf2 added in vitro mimics the action of other Fgf ligands with similar receptor binding specificity. Alternatively, it is possible that the knockout of Fgf2 in the germline allows the development of compensatory events in some CNS regions but not in the cerebral cortex. Both hypotheses are consistent with the known presence of at least 22 Fgflike ligands differentially expressed throughout the developing and adult CNS, some of which are candidates for compensatory or redundant actions (Ornitz and Itoh 2001). Fgfs may increase the generation of dividing progeny from stem cells, which is consistent with their promotion of cell divisions. In addition, their positive effect on neurogenesis and maintenance of region-specific homeodomain gene expression suggest that Fgfs are able to alter the specification of stem cells. It would be important to find out whether specific Fgfs (in conjunction with other factors) can direct the differentiation of stem cells to region-specific phenotyes.

\section{ADULT STEM CELLS}

Adult neurogenesis is a phylogenetically conserved process that has been associated with seasonal song learning in birds (Alvarez-Buylla and Kirn 1997). In the mammalian brain, new neurons arise continually from stem and progenitor cells in two specialized forebrain germinal areas: the hippocampal subgranular layer and the SVZ (Bayer et al. 1982; Lois and Alvarez-Buylla 1993; Lim et al. 1997; Temple and Alvarez-Buylla 1999).

In the adult SVZ, progenitor cells constitutively proliferate in a steady-state fashion; they are thought to arise from stem cells through transit amplifying cells (Figure 1). Although the exact lineage and mode of division of adult stem cells is unclear, their cell cycle time has been suggested to increase with age, and it is likely to be in the range of $50 \mathrm{~h}$ or more (Craig et al. 1994). In contrast, the cell cycle of neural progenitor cells is much shorter, and has been estimated to be about $13 \mathrm{~h}$ in the adult SVZ (Morshead et al. 1998; Martens et al. 2000). Progenitor cells are constitutively proliferating within the adult SVZ, and are more likely to be killed by a pulse of antimitotic agents than stem cells. This explains why after such treatments the constitutively proliferating population of the adult SVZ is repopulated after few days through an increased proliferation of stem cells and/or the transit amplifying cells (Morshead et al. 1994).

The cell cycle of progenitor cells within the adult hippocampus has been estimated to be $24 \mathrm{~h}$, with ap- 
proximately 9,000 granule cells generated each day (Cameron and McKay 2001). Hippocampal granule neurons are born continuously through life even in primates and humans, suggesting that adult neurogenesis is not confined to the rodent brain (Eriksson et al. 1998a; Kornack and Rakic 1999). Because stem cells capable of giving rise to both neurons and glia in vitro have been isolated from virtually every adult brain region, including white matter, the capability of generating nerve cells may be latent throughout the CNS (Palmer et al. 1999). We know very little about the commitment of these progenitor cells to generating region-specific cell types, their intrinsic potential to change their fate after transplantation to a different site, and conditions that may promote trans-differentiation.

Stem cells appear to be present in the SVZ in all vertebrate species tested. As in the embryo, stem cells can be isolated from many CNS regions using two growth factors that are necessary for their proliferation and survival: Epidermal Growth Factor (EGF) and Fgf2 (Reynolds et al. 1992; Reynolds and Weiss 1992; Tropepe et al. 1999). The intraventricular delivery of Fgf2 increases cell proliferation within the adult SVZ (Craig et al. 1996; Kuhn et al. 1997); however, it no longer promotes the generation of pyramidal neurons in the cerebral cortex, in contrast to its capacity to do so during embryogenesis (Vaccarino et al. 1999b). This may suggest that the neuronal progenitors that are generated in the adult SVZ are no longer specified for the production of pyramidal neurons, or they are no longer competent to respond to Fgf2 in the same way they do in the embryonic PVE (i.e., by upregulating the same set of homeodomain genes). The loss of competency is also supported by transplantation experiments in which adult progenitor/stem cells seem no longer able to reproduce the variety of neuronal phenotypes produced during embryogenesis. Although "stem cells" from the adult SVZ are able to produce generic neurons and glia in vitro, their potential to produce specific types of CNS neurons such as glutamate-containing cortical neurons or hippocampal pyramidal neurons is unclear. These highly specialized neuronal types have so far been obtained after isolation of stem/progenitor cells from their prospective embryonic CNS regions (Ray et al. 1993; Vaccarino et al. 1995). For example, SVZ cells readily differentiate and mature into thousand of new neurons and glial cells in the presence of optimal amounts of EGF or Fgf2 in vitro. However, their competence to differentiate into glutamate-containing cortical pyramidal neurons, hippocampal pyramidal cells, cholinergic neurons or other specialized, region specific phenotypes, has not been assessed.

It is also possible that rare "multipotential" stem cells persist in the CNS but their differentiation and integration into specific CNS regions is no longer permitted after the appropriate embryonic stages. For exam- ple, a number of progenitors die before differentiation. Because only a subset of these cells normally mature and differentiate into neurons in vivo, it possible that the lack of generation of pyramidal cells in the adult is due to selective factors. That is, progenitors would be generated but would not integrate into the cerebral cortex because this tissue is no longer permissive for their differentiation and maturation unless special circumstances arise locally. The cause of progenitor death has not been established, but a likely possibility is the relative lack of survival factors, combined with the presence of inhibitory signals from mature neurons and other CNS cells (see below). Against this possibility is evidence that certain embryonic cell lines can appropriately differentiate within the adult CNS (Whittemore 2000).

An understanding of the regulation of adult stem cells is closely tied to a better definition of their role and the factors that regulate their cycle. For example, it appears that cognitive factors affect progenitor cell survival in the hippocampus. Many more new neurons will survive from these progenitors in an enriched environment or in conditions of active learning (Gould et al. 1999; Kempermann and Gage 2000). Other experiments have shown that killing neuronal progenitors greatly promotes the proliferation of stem cells and their progeny, until, few days later, the entire population of dividing progenitors within the SVZ is replenished (Morshead et al. 1994). Similarly, stem and progenitor cell proliferation is stimulated by other conditions in which there is neuronal apoptosis, such as acute hypoxia/ ischemia (Liu et al. 1998).

In the developing hippocampus, the extent of granule cell neurogenesis is negatively correlated to the excitatory input to the granule cells (Gould and Cameron 1996). Gould and colleagues have shown that stress decreases cell proliferation in the hippocampal granular zone and that the negative effect of stress and adrenal hormones on hippocampal neurogenesis is mediated by a stimulation of NMDA receptors, presumably on mature granule cells (Cameron et al. 1998; Gould et al. 1998). Thus, excitatory NMDA receptors downregulate neurogenesis in adult animals, and the blockade of these receptors, in an as yet unknown manner, upregulates cell proliferation in the dentate gyrus.

The mechanisms at work in this regulation are the focus of active investigations. Current evidence suggest that hippocampal neurogenesis is promoted by chronic antidepressant treatment, which counteracts the effect of stress (Duman et al. 1999; Malberg et al. 1999) "Regulation of adult neurogenesis by antidepressant treatment by Duman et al., this issue (Duman et al. 2001). Because excitatory NMDA receptors and glucocorticoid receptors are not on progenitor cells, but on mature neurons, these results suggest that an intermediary cell must mediate the tonic inhibitory effect of differentiating as well as mature neurons on progenitor cells (Figure 3, Panel B). Be- 
cause astrocytes are profoundly affected by neuronal activity and also have been proposed to have a role in neurogenesis, it is possible that the inhibitory effects of neuronal activity on neurogenesis in the hippocampus and SVZ are mediated by the network of astroglial cells. That is, neurons would downregulate stem/progenitor cell proliferation indirectly, by inhibiting intermediary astrocytic cells whose function is to is enhance stem cell cell proliferation (Figure 3, Panel B). Although no direct evidence for this pathway has been obtained yet, it is consistent with the role of glial cells in the regulation of neurogenesis within the CNS.

These recent results raise the question of whether chronic stress may alter patterns of adult neurogenesis and may predispose to the development of mood and anxiety disorders through an action on glial cells. Intriguingly, the hippocampus of victims of post-traumatic stress disorder (PTSD) and of depressed patients is smaller than controls (Bremner et al. 1995; Bremner and Narayan 1998; Sha et al. 1998; Bremner et al. 2000). Alterations in cortical cell density have been also found in depressed subjects by postmortem morphological analyses (Ongur et al. 1998; Rajkowska et al. 1999). The causes of these morphological effects are not clear: are they possibly due to a degenerative process or to a lack of neurogenesis, leading to a failure of normal turnover in hippocampal cell number? Whatever the mechanism, antidepressant may exert their beneficial effect in part through a reversal of this process.

Thus, an epigenetic condition that is likely to affect the generation of new cells is cell death (see "Manipulation of neural precursors in situ: Induction of neurogenesis in the neocortex of adult mice" by Magavi and Macklis, this issue (Magavi and Macklis, 2001). In keeping with the above concepts, the induction of apoptotic death in cortical pyramidal neurons may provide an appropriate environment for the generation and migration of cortical progenitor cells. For example, apoptotic cell death may induce the re-expression in the mature brain of developmental signals that control proliferation, survival, differentiation and migration of progenitor cells (Sheen and Macklis 1995). Multiple signals, again originating from mature neurons, are likely to affect these events, possibly reiterating, in the mature brain, gene cascades that occur at earlier stages of development (Vaccarino 2000).

\section{STEM CELLS AND CNS REGENERATION}

Regeneration and plasticity is a function shared by many phylogenetically older species, which has been so far thought to be incompatible with the stability of mammalian brain and advanced mental abilities. However, the brain may share with other organs regenera- tive mechanisms that will attempt to replace what is lost after various forms of damage.

Converging evidence suggests that regenerative responses may involve astrocytes. It has been recently proposed that stem cells belong to the glial lineage, because GFAP-immunoreactive astrocytes within the SVZ have characteristics consistent with stem cells both in vitro and in vivo (Doetsch et al. 1999; Laywell et al. 2000). An alternative theory is for ependymal cells to be stem cells (Johansson et al. 1999). Remarkably, two Fgf receptors are expressed by these non-neuronal cells in the postnatal brain: Fgfr-1 is expressed by the ependyma and Fgfr-2 by SVZ astrocytes (Figure 4). The Fgfr-1 protein is almost undetectable under basal condition, and greatly upregulated by CNS insults, particularly acute and chronic hypoxia (Ganat et al., submitted). As noted above, Fgf2 and Fgfr-1 are critical for the proliferation or survival of embryonic forebrain stem cells in vitro and in vivo.

In hypoxia and other forms of injury, astrocytes undergo a complex series of changes (Ridet et al. 1997). Nuclear Fgf2 expression is enhanced in astrocytes under hypoxia, and Fgf2-positive astrocytes increase in number throughout the brain (Frautschy et al. 1991; Endoh et al. 1994; Hara et al. 1994; Ganat et al., submitted). After several days of chronic hypoxia, there is a decrease in GFAP staining throughout the cerebral cortex and an increase expression of vimentin and Brain Lipid Binding Protein (BLBP), two markers for radial glia, in astrocytic cells near the SVZ (Ganat et al., submitted). Because vimentin decreases and GFAP increases as the astrocytes mature, these results suggest that astrocytes revert to a more immature form of glia after prolonged periods of hypoxic stress. Previous work has suggested that mature astrocytes transform into radial glia if exposed to soluble factors present in the embryonic brain (Hunter and Hatten 1995).

During embryonic development, radial glia divide, produce neurons (Noctor et al. 2001) and express Fgfr-1 (Figure 4, Panel A). The increased presence of radial glia in chronic hypoxia suggests an ongoing regenerative response in which the generation of neuronal progenitors from stem cells may be increased. Proliferation or survival of radial glia may be promoted by the upregulation of Fgfr-1 in these cells seen in hypoxia. Consistent with this hypothesis, Fgf2, which binds to Fgfr-1, is necessary and sufficient to promote neurogenesis in the hippocampus after brain insults (Yoshimura et al. 2001). Understanding the mechanisms of this attempt at cell replacement may allow us to promote brain repair in a way so far thought impossible.

In conclusion, Fgf2 and other growth factors may be necessary for both embryonic and adult neurogenesis, but the progenitors that express Fgf receptors may be differentially specified by cell-intrinsic factors to generate different types of cells. It remains to be determined to what extent these developmental rules may be changed under conditions of brain injury. 

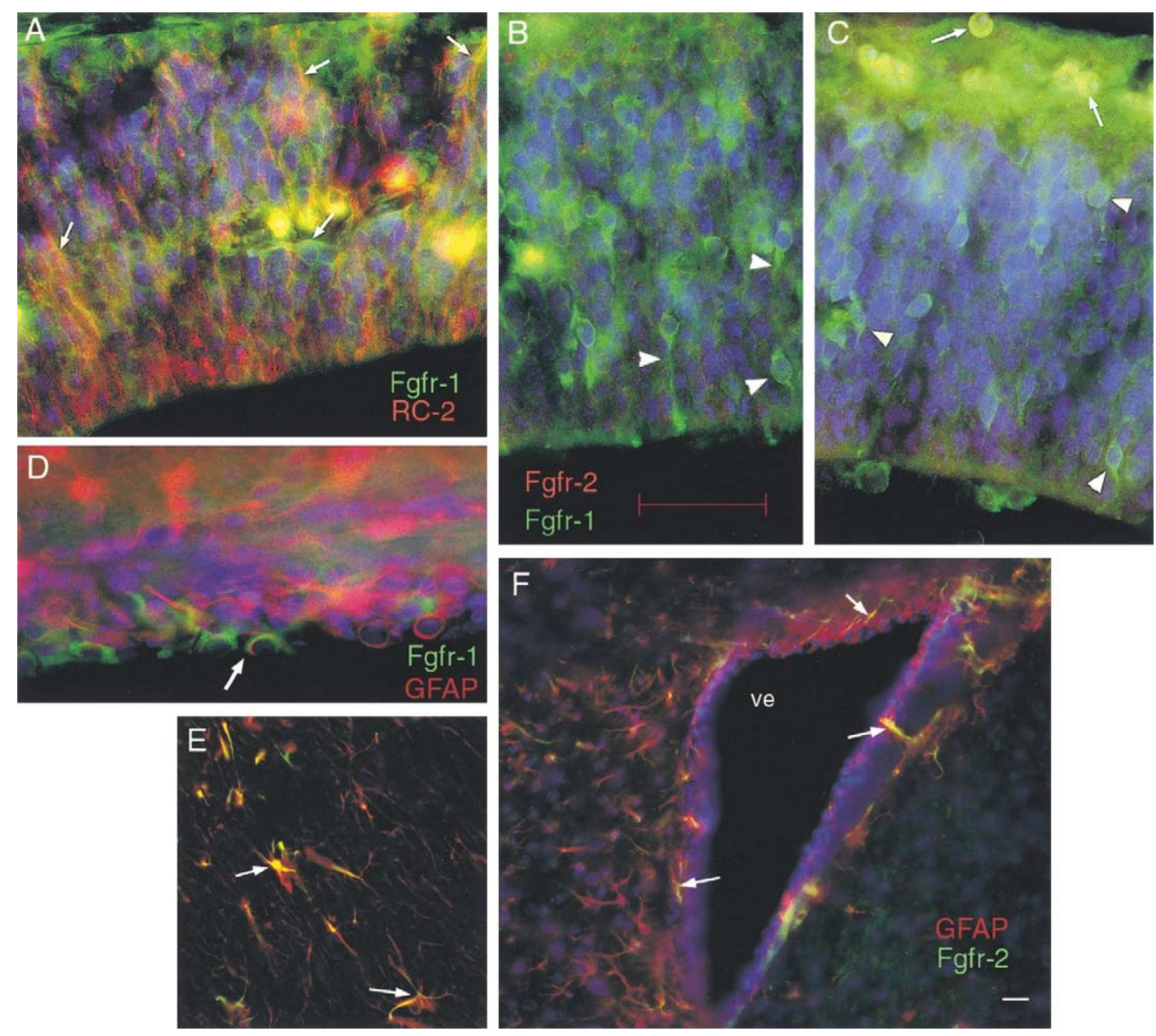

Figure 4. Location and characterization of Fgf receptors in neuronal progenitor/stem cells. Fgf receptors in the mouse dorsal telencephalic neuroepithelium (Panels A-C) and in the adult SVZ (Panels D-F). Panel A: Double immunostaining for Fgfr-1 (green) and the RC-2 monoclonal antibody, a marker for radial glia in the PVE at E12.5. Arrows show double-stained cells. Panels B and C: Double immunostaining for Fgfr-1 (green) and Fgfr-2 (red). Most radial glial cells are positive only for Fgfr-1(arrowheads); mesodermal elements and vascular cells are double-stained (arrows). Panel D. Double immunostaining for Fgfr-1 (green) and GFAP (red) in the postnatal SVZ. Fgfr-1 is expressed by scattered ependymal cells and only occasionally co-localized with GFAP, a marker for astrocytes (arrow). Panels E and F. Double immunostaining of Fgfr-2 (green) and GFAP (red) in the adult mouse SVZ. Fgfr-2 is expressed by a subset of astrocytes (arrows), which are normally non-dividing. Scale bar, $50 \mu \mathrm{m}$ in Panels A-C and $20 \mu \mathrm{m}$ in Panels D-F.

\section{IS THE BRAIN EVER “STABLE”?}

A stable neural network does not learn. Thus, some kind of instability must be "embedded" within the largely stable structure of the CNS, particularly in the forebrain. In agreement with this, the most extensive changes in cell number and synapses due to cell death and synaptic pruning occur in infancy, during the most active period of learning. Synapse formation is associated with critical periods for the acquisition of sensorimotor functions, emotional competence and language abilities. Evidence is accumulating that constant reorganization of synaptic connections occurs even in adolescence and adults. In the hippocampus, cyclic variations in cell proliferation and the density of synapses occur in connections with cyclic variations in the hormonal milieu (Tanapat et al. 1998). Thousands of new granule cells are born within the hippocampus each day and some may eventually connect to the CA3 pyramidal cells, suggesting extensive network reorganization during adulthood (Markakis and Gage 1999; Cameron and McKay 2001). Thus, it appears that some regions are set by infancy, and others are the site of late and/or constant reorganization. It would be interesting to find out whether the birth of new cells, which may be associated with learning, is driven by the re-expression of developmentally regulated transcription factors in these regions of the adult brain. 


\section{REFERENCES}

Altman J (1962): Are new neurons formed in the brains of adult mammals? Science 135:1127-1128

Altman J, Das GD (1966): Autoradiographic and histological studies of postnatal neurogenesis. J Comparative Neurology 126:337-389.

Alvarez-Buylla A, Kirn JR (1997): Birth, migration incorporation, and death of vocal control neurons in adult songbirds. J Neurobiol 33:585-601

Anderson DJ (2001): Stem Cells and Pattern Formation in the Nervous System: The Possible versus the Actual. Neuron 30:19-35

Bayer SA, Yackel JW, Puri PS (1982): Neurons in the rat dentate gyrus granular layer substantially increase during juvenile and adult life. Science 216:890-892

Beddington RSP, Robertson EJ (1999): Axis development and early asymmetry in mammals. Cell 96:195-209

Bjornson CR, Rietze RL, Reynolds BA, Magli MC, Vescovi AL (1999): Turning brain into blood: a hematopoietic fate adopted by adult neural stem cells in vivo. Science 283:534-537

Bremner JD, Narayan M (1998): The effects of stress on memory and the hippocampus throughout the life cycle: implications for childhood development and aging. Development and Psychopathology 10:871-886

Bremner JD, Narayan M, Anderson ER, Staib LH, Miller HL, Charney DS (2000): Hippocampal volume reduction in major depression. Am J Psychiatry 157:115-118

Bremner JD, Randall PR, Scott TM, Bronen RA, Delaney RC, Seibyl JP, Southwick SM, McCarthy G, Charney DS, Innis RB (1995): MRI-based measurement of hippocampal volume in posttraumatic stress disorder. Am J Psychiatry 152:973-981

Calof AL, Rim PC, Askins KJ, Mumm JS, Gordon MK, Iannuzzelli P, Shou J (1998): Factors regulating neurogenesis and programmed cell death in the mouse olfactory epithelium. Ann N Y Acad Sci 855:226-229

Cameron HA, McKay R (2001): Adult neurogenesis produces a large pool of new granule cells in the dentate gyrus. J Comp Neurol 435:406-417

Cameron HA, Tanapat P, Gould E (1998): Adrenal steroids and N-methyl-D-aspartate receptor activation regulate neurogenesis in the dentate gyrus through a common pathway. Neuroscience 82:349-354

Cameron HA, Wooley CS, McEwen BS, Gould E (1993): Differentiation of newly born neurons and glia in the dentate gyrus of the adult rat. Neuroscience 56:337-344

Craig CG, Morshead CM, Roach A, van der Kooy D (1994): Evidence for a relatively quiescent stem cell in the adult mammalian forebrain. J Cell Biochem 18:176

Craig CG, Tropepe V, Morshead CM, Reynolds BA, Weiss S, van der Kooy D (1996): In vivo growth factor expansion of endogenous subependymal neural precursor cell populations in the adult mouse brain. J Neurosci 16: 2649-2658

Crossley PH, Martinez S, Martin GR (1996): Midbrain development induced by FGF8 in the chick embryo. Nature 380:66-68

Davis AD, Temple S (1994): A self-renewing multipotential stem cell in embryonic rat cerebral cortex. Nature 372: 263-266

Doetsch F, Caille I, Lim DA, Garcia-Verdugo JM, AlvarezBuylla A (1999): Subventricular zone astrocytes are neural stem cells in the adult mammalian brain. Cell 97:703-716

Duman RS, Malberg J, Thorne J (1999): Neural plasticity to stress and antidepressant treatment-role of BDNF. Biol Psychiatry 46:1181-1191

Duman RS, Nakagawa S, Malberg J (2001): Regulation of adult neurogenesis by antidepressant treatment. 25:836-844

Endoh M, Pulsinelli WA, Wagner JA (1994): Transient global ischemia induces dynamic changes in the expression of bFGF and the FGF receptor. Brain Res MolBrain Res 22:76-88

Ericson J, Rashbass P, Shedl A, Brenner-Morton S, Kawakami A, van Heyningen V, Jessel TM, Briscoe J (1997): Pax6 controls progenitor cell identity and neuronal fate in response to graded Shh signaling. Cell 90:169-180

Eriksson PS, Perfilieva E, Bjork-Eriksson T, Alborn AM, Nordborg C, Peterson DA, Gage FH (1998a): Neurogenesis in the adult human hippocampus. Nat Med 4:1313-1317

Eriksson PS, Perfilieva E, Bjork-Eriksson T, Alborn AM, Nordborg C, Peterson DA, Gage FH (1998b): Neurogenesis in the adult human hippocampus. Nat Med 4:1313-1317

Frantz GD, Weimann JM, Levin ME, McConnell SK (1994): Otx1 and Otx2 define layers and regions in developing cerebral cortex and cerebellum. J Neurosci 14:5725-5740

Frautschy SA, Walicke PA, Baird A (1991): Localization of basic fibroblast growth factor and its mRNA after CNS injury. Brain Res 553:291-299

Galli R, Borello U, Gritti A, Minasi MG, Bjornson C, Coletta M, Mora M, De Angelis MG, Fiocco R, Cossu G, Vescovi AL (2000): Skeletal myogenic potential of human and mouse neural stem cells. Nat Neurosci 3:986-991

Ganat Y, Soni S, Chacon M, Schwartz ML, Vaccarino FM (submitted) Chronic hypoxia upregulates Fibroblast Growth Factor (Fgf) ligands in the perinatal brain and induces Fgf-responsive radial glial cells in the subependymal zone. Neuroscience.

Gould E, Tanapat AJ (1997): Lesion-induced proliferation of neuronal progenitors in the dentate gyrus of the adult rat. Neuroscience 80:427-436

Gould E, Cameron HA (1996): Regulation of neuronal birth, migration and death in the rat dentate gyrus. Dev Neurosci 18:22-35

Gould E, Tanapat P, McEwen BS, Flugge G, Fuchs E (1998): Proliferation of granule cell precursors in the dentate gyrus of adult monkeys is diminished by stress. Proc Natl Acad SciUSA 95:3168-3171

Gould E, Beylin A, Tanapat P, Reeves A, Shors TJ (1999): Learning enhances adult neurogenesis in the hippocampal formation. Nat Neurosci 2:260-265

Gurdon JB (1988): A community effect in animal development. Nature 336:772-774

Gurdon JB, Lemaire P, Kato K (1993): Community effects and related phenomena in development. Cell 75:831-834

Hara Y, Tooyama I, Akiyama H, McGeer PL, Handa J, Kimura H (1994): Acidic fibroblast growth factor-like immunoreactivity in rat brain following cerebral infarction. Brain Res 664:101-107 
Hemmati-Brivanlou A, Melton D (1997): Vertebrate embryonic cells will become nerve cells unless told otherwise. Cell 88:13-17

Hongo I, Kengaku M, Okamoto H (1999): FGF signaling and the anterior neural induction in Xenopus. Devel Biol 216: $561-581$

Hunter KE, Hatten ME (1995): Radial glial cell transformation to astrocytes is bidirectional: regulation by a diffusible factor in embryonic forebrain. Proc Natl Acad Sci USA 92:2061-2065

Hynes M, Porter JA, Chiang C, Chang D, Tessier-Lavigne M, Beachy PA, Rosenthal A (1995): Induction of midbrain dopaminergic neurons by sonic hedgehog. Neuron 15: 35-44

Jessel TM, Lumsden A (1997): Inductive signals and the assignment of cell fate in the spinal cord and hindbrain. In Cowan WM, Jessel TM, Zipursky SL (eds), Molecular and cellular approaches to neural development. Oxford, Oxford University Press, pp 290-333

Johansson CB, Momma S, Clarke DL, Risling M, Lendhal U, Frisen J (1999): Identification of a neural stem cell in the adult mammalian central nervous system. Cell 96:25-34

Kempermann G, Gage FH (2000): Experience-dependent regulation of adult hippocampal neurogenesis: Effects of long-term stimulation and stimulus withdrawal. Hippocampus 9:321-332

Korada S, Zheng W, Basilico C, Schwartz ML, Vaccarino FM (submitted): Fgf2 is necessary for the growth of glutamate projection neurons in the anterior neocortex. J Neurosci

Kornack DR, Rakic P (1999): Continuation of neurogenesis in the hippocampus of the adult macaque monkey. Proc Natl Acad Sci USA 96:5768-5773

Kuhn HG, Winkler J, Kempermann G, Thal L, Gage FH (1997): Epidermal growth Factor and Fibroblast Growth Factor-2 have different effects on neural progenitors in the adult rat brain. J Neurosci 17:5820-5829

Laywell E, Rakic P, Kukekov VG, Holland EC, Steindler DA (2000): Identification of a multipotent astrocytic stem cell in the immature and adult mouse brain. Proc Natl Acad Sci USA 97:13883-13888

Lee SMK, Danielian PS, Fritzsch B, McMahon AP (1997): Evidence that FGF8 signaling from the midbrain-hindbrain junction regulates growth and polarity in the developing midbrain. Development 124:959-969

Lim DA, Fishell GJ, Alvarez-Buylla A (1997): Postnatal mouse subventricular zone neuronal precursors can migrate and differentiate within multiple levels of the developing neuraxis. Proc Natl Acad Sci USA 94:14832-14836

Liu A, Joyner AL (2001): EN and GBX2 play essential roles downstream of FGF8 in patterning the mouse mid/ hindbrain region. Development 128:181-191

Liu A, Losos K, Joyner AL (1999): FGF8 can activate Gbx2 and transform regions of the rostral mouse brain into a hindbrain fate. Development 126:4827-4838

Liu J, Solway K, Messing RO, Sharp FR (1998): Increased neurogenesis in the dentate gyrus after transient global ischemia in gerbils. J Neurosci 18:7768-7778

Lois C, Alvarez-Buylla A (1993): Proliferating subventricular zone cells in the adult mammalian forebrain can differentiate into neurons and glia. ProcNatl AcadSciUSA 90: 2074-2077
Lumsden A (1991): Cell lineage restrictions in the chick embryo hindbrain. [Review]. Phil Trans R Soc Lond 331: 281-286

Luskin MB (1993): Restricted proliferation and migration of postnatally generated neurons derived from the forebrain ventricular zone. Neuron 11:173-189

Magavi SS, Macklis JD (2001): Manipulation of neural precursors in situ: induction of neurogenesis in the neocortex of adult mice. Neuropsychopharmacology 25:816-835

Malatesta P, Harfuss E, Gotz M (2000): Isolation of radial glial cells by fluorescent-activated cell sorting reveals a neuronal lineage. Development 127:5253-5263

Malberg JE, Eissch AJ, Nestler EJ, Duman RS (1999): Chronic antidepressant administration increases granule cell neurogenesis. Society for Neuroscience Abstract 25:1029

Markakis EA, Gage FH (1999): Adult-generated neurons in the dentate gyrus send axonal projections to field CA3 and are surrounded by synaptic vescicles. J Compar Neurol 406:449-460

Martens DJ, Tropepe V, van der Kooy D (2000): Separate proliferation kinetics of fibroblast growth factor-responsive and epidermal growth factor-responsive neural stem cells within the embryonic forebrain germinal zone. J Neurosci 20:1085-1095

Martinez S, Crossley PH, Cobos I, Rubenstein JLR, Martin GR (1999): FGF8 induces formation of an ectopic isthmic organizer and isthmocerebellar development via a repressive effect on Otx2 expression. Development 126:1189-1200

Mayer-Proeschel M, Kalyani AJ, Mujtaba T, Rao MS (1997): Isolation of lineage-restricted neuronal precursors from multipotent neuroepithelial cells. Neuron 19:773-785

McConnell SK (1990): The specification of neuronal identity in the mammalian cerebral cortex. Experientia 46: 922-929

McKay R (1997): Stem cells in the central nervous system. Science 276:66-71

McMahon A, Bradley A (1990): The Wnt-1 (int-1) protooncogene is required for development of a large region of the mouse brain. Cell 62:1073-1085

Meyers EN, Lewandoski M, Martin GR (1998): An Fgf8 mutant allelic series generated by Cre-and Flp-mediated recombination. Nature Gen 18:136-141

Morshead CM, Craig CG, van der Kooy D (1998): In vivo clonal analyses reveal the properties of endogenous neural stem cell proliferation in the adult mammalian forebrain. Development 125:2251-2268

Morshead CM, Reynolds BA, Craig CG, McBurney MW, Staines WA, Morassutti D, Weiss S, van der Kooy D (1994): Neural stem cells in the adult mammalian forebrain: a relatively quiescent subpopulation of subependimal cells. Neuron 13:1071-1082

Niwa H, Miyazaki J, Smith AG (2000): Quantitative expression of Oct-3/4 defines differentiation, de-differentiation or self-renewal of ES cells. Nature Gen 24: 372-376

Noctor SC, Flint AC, Weissman TA, Dammerman RS, Kriegstein AR (2001): Neurons derived from radial glial cells establish radial units in neocortex. Nature 409:714-720

Olsson M, Campbell K, Turnbull DH (1997): Specification of mouse telencephalic and mid-hindbrain progenitors following heterotopic ultrasound-guided embryonic transplantation. Neuron 19:761-772 
Ongur D, Drevets WC, Price JL (1998): Glial reduction in the subgenual prefrontal cortex in mood disorders. Proc Natl Acad SciUSA 95:13290-13295

Ornitz D, Itoh N (2001): Fibroblast growth factors. Genome Biology 2:3005-3012

Ortega S, Ittmann M, Tsang SH, Ehrich M, Basilico C (1998): Neuronal defects and delayed wound healing in mice lacking fibroblast growth factor 2. Proc Natl Acad Sci USA 95:5672-5677

Palmer TD, Markakis EA, Willhoite AR, Safar F, Gage FH (1999): Fibroblast Growth Factor-2 activates a latent neurogenic program in neural stem cells from diverse regions of the adult CNS. J Neurosci 19:8487-8497

Pownall ME, Tucker AS, Slack JMW, Isaacs HV (1996): eFGF, $X c a d 3$ and Hox genes form a molecular pathway that establishes the anteroposterior axis in Xenopus. Development 122:3881-3892

Puelles L, Rubenstein JL (1993): Expression patterns of homeobox and other putative regulatory genes in the embryonic mouse forebrain suggest a neuromeric organization. TINS 16:472-479

Raballo R, Rhee J, Lyn-Cook R, Leckman JF, Schwartz ML, Vaccarino FM (2000): Basic fibroblast growth factor (Fgf2) is necessary for cell proliferation and neurogenesis in the developing cerebral cortex. J Neurosci 20:5012-5023

Rajkowska G, Miguel-Hildago JJ, Wei J, Dilley G, Pittman SD, Melzer HY, Overholser JC, Roth BL, Stockeimer CA (1999): Morphometric evidence for neuronal and glial prefrontal cell pathology in major depression. Biol Psychiatry 45:1085-1098

Ray J, Gage FH (1994): Spinal cord neuroblasts proliferate in response to basic fibroblast growth factor. J Neurosci 14:3548-3564

Ray J, Peterson DA, Schinstine M, Gage FH (1993): Proliferation, differentiation, and long-term culture of primary hippocampal neurons. Proc Natl Acad Sci USA 90:36023606

Reynolds BA, Weiss S (1992): Generation of neurons and astrocytes from isolated cells of the adult mammalian central nervous system. Science 255:1707-1710

Reynolds BA, Tetzlaff W, Weiss S (1992): A multipotent EGF-responsive striatal embryonic progenitor cell produces neurons and astrocytes. J Neurosci 12:4565-4574

Richards LJ, Kilpatrick TJ, Bartlett PF (1992): De novo generation of neuronal cells from the adult mouse brain. Proc Natl Acad Sci USA 89:8591-8595

Ridet JL, Malhotra SK, Privat A, Gage FH (1997): Reactive astrocytes: cellular and molecular cues to biological function. Trends Neurosci 20:570-577

Robel L, Ding M, James AJ, Lin X, Leckman JF, Vaccarino FM (1995): Fibroblast growth factor 2 increases Otx2 expression in precursor cells from the mammalian telencephalon. J Neurosci 15:7879-7891

Rubenstein JLR, Shimamura K (1997): Regulation of patterning and differentiation in the embryonic vertebrate forebrain. In Cowan WM, Jessel TM, Zipursky SL (eds), Molecular and cellular approaches to neural development, $1^{\text {st }}$ ed. New York: Oxford University Press, pp 356-390
Sha PJ, Ebmeier KP, Glabus MF, Goodwin GM (1998): Cortical gray matter reductions associated with treatmentresistant chronic unipolar depression. Arch Gen Psychiatry 527:532

Sheen VL, Macklis JD (1995): Targeted neocortical cell death in adult mice guides migration and differentiation of transplanted embryonic neurons. J Neuroscience 15: 8378-8392

Simeone A, Acampora D, Gulisano M, Stornaiuolo A, Boncinelli E (1992): Nested expression domains of four homeobox genes in developing rostral brain. Nature 358:687-690

Suhonen JO, Peterson DA, Gage FH (1996): Differentiation of adult hippocampus-derived progenitors into olfactory neurons in vivo. Nature 383:624-627

Takahashi T, Nowakowski RS, Caviness VS (1996): The leaving or $\mathrm{Q}$ fraction of the murine cerebral proliferative epithelium: a general model of neocortical neuronogenesis. J Neurosci 16:6183-6196

Tanapat AJ, Hastings NB, Reeves AJ, Gould E (1998): Estrogen stimulates the proliferation of granule cell precursors in the dentate gyrus of adult female rats. Neuroscience Abstracts 24:796-798.

Temple S, Alvarez-Buylla A (1999): Stem cells in the adult mammalian central nervous system. Curr Opinion Neurobiol 9:135-141

Tropepe V, Sibilia M, Ciruna BG, Rossant J, Wagner EF, van der Kooy D (1999): Distinct neural stem cells proliferate in response to EGF and FGF in developing mouse telencephalon. Devel Biol 208:166-188

Tropepe V, Hitoshi S, Sirad C, Mak TW, Rossant J, van der Kooy D (2001): Direct neural fate specification from embryonic stem cells: a primitive mammalian neural stem cell stage acquired through a default mechanism. Neuron 30:65-78

Vaccarino FM (2000): Stem cell diversity in the developing CNS. The Neuroscientist 6:338-352

Vaccarino FM, Schwartz ML, Hartigan D, Leckman JF (1995): Effect of basic fibroblast growth factor on the genesis of excitatory and inhibitory neurons in primary cultures of cells from the mammalian telencephalon. Cereb Cortex 1:64-78

Vaccarino FM, Schwartz ML, Raballo R, Rhee J, Lyn-Cook R (1999a): Fibroblast Growth Factor signaling regulates growth and morphogenesis at multiple steps during brain development. In Pedersen RA, Shatten G (eds), Current Topics in Developmental Biology. Vol 46 San Diego, CA, Academic Press, pp 179-200

Vaccarino FM, Schwartz ML, Raballo R, Nilsen J, Rhee J, Zhou M, Doetschman T, Coffin JD, Wyland JJ, Hung Y-TE (1999b): Changes in cerebral cortex size are governed by fibroblast growth factor during embryogenesis. Nat Neurosci 2:246-253

Whittemore SR (2000): Immortalized neural cell lines for CNS transplantation. Prog Brain Res 127:49-65

Yoshimura S, Takagi Y, Harada J, Teramoto T, Thomas SS, Waeber C, Bakowska J, Breakefield XO, Moskowitz MA (2001): FGF-2 regulation of neurogenesis in adult hippocampus after brain injury. Proc Natl Acad Sci USA 98:5874-5879 